\title{
Research on Urban Environment System Based on Complex and Uncertainty Theory
}

\author{
Min Zhu ${ }^{1}$, Yanglei $\mathrm{Ou}^{2}$ \\ 1. Pingxiang University, Pingxiang, Jiangxi, 337055, China \\ 2. Pingxiang Power Supply Company, Pingxiang, Jiangxi, 337055, China
}

Keywords: ecological city; uncertainty theory; inexact fuzzy multi-objective programming(IFMOP); resource allocation

\begin{abstract}
An inexact-based fuzzy multi-objective programming (IFMOP) model is developed based on analysis of fuzzy information and multi-objective characteristics of an ecological city. In the IFMOP model, parameters originally based on certain targets and accurate objectives are now obtained as interval numbers. Through the interactive process between decision makers and the interpretation of the model, some reasonable solutions can be achieved by using MATLAB programming. This study took a new development zone in a city of North China as a case study, a reasonable water resource allocation scheme in 2020 is obtained, illustrating the practicability of this model.
\end{abstract}

\section{Introduction}

Any city planning, the optimal allocation of water resources is one of the important links. With China's economic and social development, how to improve the functional requirements of the city, eco-city research and construction practice has taken more and more people's attention. And some experience has been achievedin the construction of eco-city economic, social and ecological development of the characteristics of its decision on the optimal allocation of water resources higher requirements[1-2].

Eco-city, different from the general concept of the city, it is not a closed system, but a complex system involving urban natural ecosystems, urban artificial environment systems, economic systems and social systems [3-5]. It requires both to ensure the sustained economic growth rate, but also to ensure the quality of economic growth, while the ecological city but also to meet the basic needs of residents[6]. It can be said that the ecological city is a social, economic and environmental unity. The optimal allocation of water resources to pay more attention to the simultaneous development of human and ecological environment, the importance of ecological water and water resources, ecological value[7-8]. Therefore, the optimal allocation of eco-city water resources not only to consider the city system itself is comprehensive, complex, and uncertainty, but also consider the ecological water demand and ecological value in the time of the dynamic, the ambiguity of the data, and interaction with other factors and other characteristics of interaction, is an uncertain multi-objective programming problem[9].

\section{IFMOP model and its solution}

Uncertainty fuzzy multi-objective model (IFMOP) is an extension of uncertainty multi-objective model (IMOP), which applies the theory and method of fuzzy mathematics to IMOP model, further improves the certainty of IMOP, Reliability and validity[10]. At the same time, IFMOP can also be regarded as the result of the expansion of the original uncertain fuzzy linear programming (IFLP) model to multi-objective decision problem, which is a system that integrates IFLP with FMOP Optimization methods, so the IFMOP model has its unique advantages in dealing with the planning problems of complex environmental systems[11]. 


\section{Model description}

In general, the general form of the IFMOP model is expressed as follows:

$$
\left\{\begin{array}{l}
\min f_{k}^{ \pm}=C_{k}^{ \pm} X^{ \pm}, k=1,2, \cdots, u \\
\max f_{l}^{ \pm}=C_{l}^{ \pm} X^{ \pm}, l=u+1, u+2, \cdots, q \\
A_{i}^{ \pm} X^{ \pm} \leqslant b_{i}^{ \pm}, i=1,2, \cdots, m \\
A_{j}^{ \pm} X^{ \pm} \geqslant b_{j}^{ \pm}, j=m+1, m+2, \cdots, n \\
X^{ \pm \geqslant 0}
\end{array}\right.
$$

Where $f_{k}^{ \pm}, f_{l}^{ \pm}$are minimized and maximized objective functions, respectively; $u, q$ are the dimension of the target coefficient and the total coefficient dimension respectively; $C_{l}^{ \pm}$is called the benefit coefficient $A_{i}^{ \pm}, A_{j}^{ \pm}, \in R_{1 \times t}^{ \pm} ; X^{ \pm}$called decision variable, $X^{ \pm} \in R_{1 \times t}^{ \pm} ; m, n$ are the maximum target constraint dimension and the total constraint dimension respectively; $R_{ \pm}$is the set of indeterminate numbers. An interval where the upper and lower bounds are known but the distribution information is unknown, that is, $x_{ \pm}=\left[x^{-}, x^{+}\right]=\left\{t \in x \mid x^{-} \leqslant t \leqslant x^{+}\right\}$.

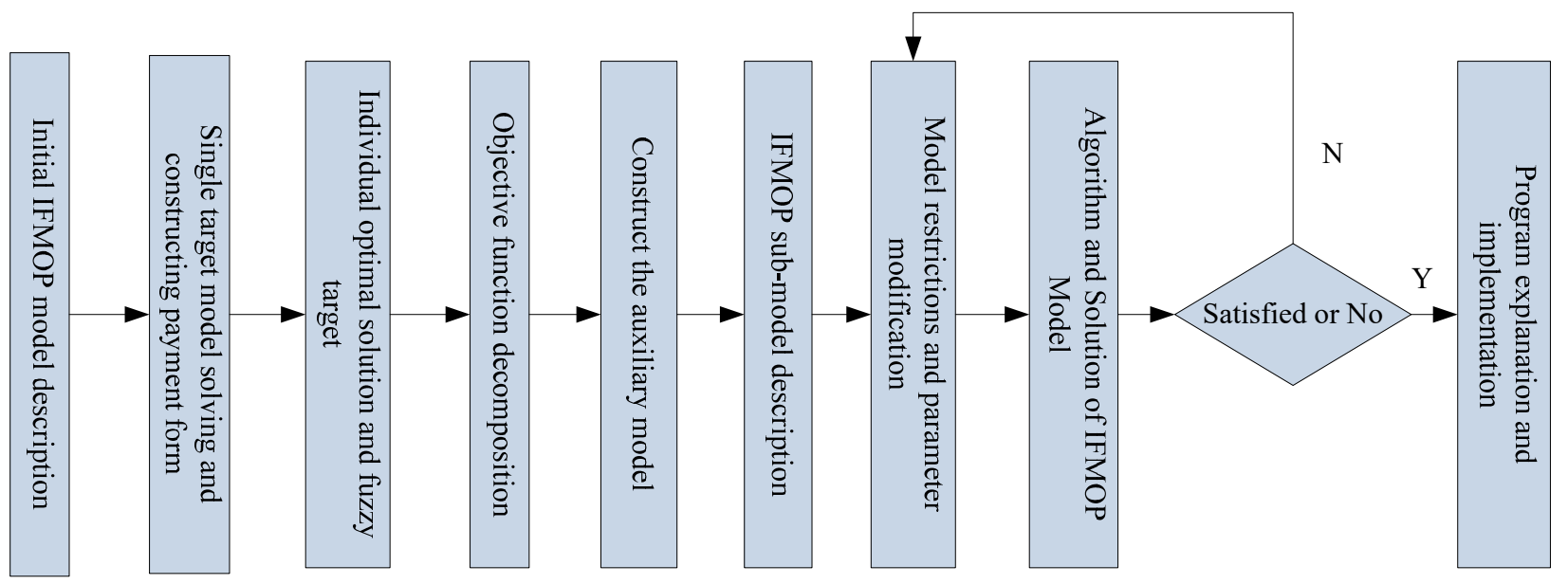

Figure 1. The solving process of IFMOP model

\section{Model solution}

The model structure can be seen from the model structure described in section 1.1. The method of solving the model has been studied by many scholars. The general idea is that the fuzzy objective is used to identify the fuzzy target, and then the FLP conversion, fuzzy target construction, ILP conversion, fuzzy objective decomposition and IFMOP sub-model construction are used to solve the model. The IFMOP model solution flow is shown in Figure 1. The specific steps can be found in Guo Huai-chen's "Environmental Planning Method and Application" (2006) and related literature[12].

\section{The choice of solution}

Some nonnegative solutions of uncertain multi-objective programming models can be obtained by solving the model, but these non-inferior solutions can not directly generate the planning scheme, because the mathematical model is only the simplification of the objective world and can not fully represent the actual system itself. The model results and decision-makers experience, expert knowledge get as reasonable as possible to optimize the decision-making program[13].Therefore, there is an interactive process, that is, the non-inferior solution submitted to the decision-makers to analyze and evaluate the decision maker feedback to the model, the appropriate correction of the model, and then repeated solution until a satisfactory solution. 


\section{Case study}

\section{Analysis on water supply and demand balance in some city of north China}

In this paper, a new urban area is located in the lower reaches of a water system in North China, which is close to the Bohai Sea and has a complicated river system. It is currently available for water resources from local groundwater, local surface water, groundwater, surface water, recycle water, and desalination of seawater. However, compared with the rapid development of the city, the water is still relatively insufficient. Coupled with the water resources efficiency is not balanced and poor water quality problems, resource-based water shortage is more serious, contradictory supply and demand. Mainly rely on the administrative plan of water-saving, economic regulation and public participation is insufficient.Therefore, on the one hand through the drinking water source project, transformation of urban water supply pipe network project, increase the use of seawater, promote water-saving technology to increase water supply, and on the other hand need to strengthen the optimal allocation of water resources and water conservation, and guide the rational use of efficient water conservation.

The water supply and water requirements for the year are shown in Table 1 and Table 2.

Table 1 . The prediction of water supply of the case study area in 2020

\begin{tabular}{|c|c|c|c|c|c|c|}
\hline \multicolumn{7}{|c|}{0.1 billion $\mathrm{m}^{3}(\mathrm{a}-1)$} \\
\hline \multicolumn{2}{|c|}{ local } & \multicolumn{2}{|c|}{ Out of tune } & \multicolumn{2}{|c|}{ seawater } & recycled \\
\hline surface water & groundwater & surface water & groundwater & surface water & groundwater & water \\
\hline 0.40 & 0 & 8.28 & 0 & 2.16 & 0.64 & 5.80 \\
\hline
\end{tabular}

Table 2. The prediction of water demand of the case study area in 2020

10 thousands $\mathrm{m}^{3}(\mathrm{a}-1)$

\begin{tabular}{|c|c|c|c|c|c|c|c|}
\hline \multicolumn{4}{|c|}{ produce } & \multicolumn{2}{|c|}{ living } & \multirow[b]{2}{*}{ Ecology } & \multirow[b]{2}{*}{ others } \\
\hline agriculture & industry & building & $\begin{array}{l}\text { tertiary } \\
\text { Industry }\end{array}$ & urban & rural & & \\
\hline 11140.00 & 108000.00 & 12000.00 & 15126.96 & 23033.00 & 520.00 & 7279.45 & 2355.40 \\
\hline
\end{tabular}

\section{IFMOP model of water resources planning in a new city}

In this paper, the benefit coefficient and cost coefficient of the literature and information, select the user million output value of the reciprocal to determine the different water users benefit coefficient. The cost factor of the various types of water resources or the cost factor of the similar water source project in the adjacent area to determine the cost factor. According to the water supply and demand balance analysis, Is $95.79 \%$, considering the principle of basic theory of uncertainty and the present situation for less than needed, and to solve the model, the lower limit of water demand is $\alpha-j=0.9(j=1,2, \ldots, 8)$, the upper limit of water demand is $\alpha+j=1(j=1,2, \ldots, 8)$.

\section{IFMOP model to solve the results and discussion}

Based on the objective function decomposition of the model, combined with the interactive algorithm and theory, the solution of the IFMOP model of the optimal allocation of water resources in 2020 is obtained by the MATLAB software.

In order to show the results of the optimal allocation of water resources in 2020, the intermediate value of the configuration interval (the value is taken by itself) can be plotted as shown in Figure 2 and Figure 3.

(1) Industry is the largest water demand sector, as shown in Figure 3. Water demand in the industrial sector accounts for about $60 \%$ of the total water demand in all sectors. If the amount of industrial water is reduced, the effect of reducing total water demand will be solved. So it is the most important way to improve the utilization of water resources by optimizing the industrial structure, improving the efficiency of industrial water use and improving the water saving work.

(2) Agricultural water is given priority from the local surface water, the difference is taken from the external control of surface water. Urban and rural living water mainly from the external surface water, at the same time, in order to maintain water quality, part of urban life water which has lower requirements of water quality can be replaced by recycled water. Water for the tertiary industry is taken from the direct use and desalination of groundwater, reclaimed water and seawater, and priority 
is given to reclaimed water reuse and seawater. Ecological water's demand is low, should be completely taken from the recycled water, as shown in Figure 3.

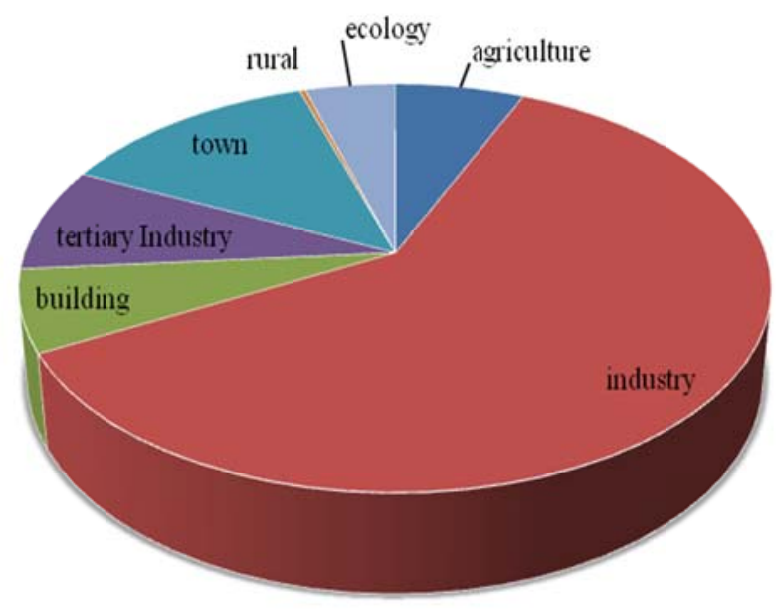

Figure 2. Water distribution in each section

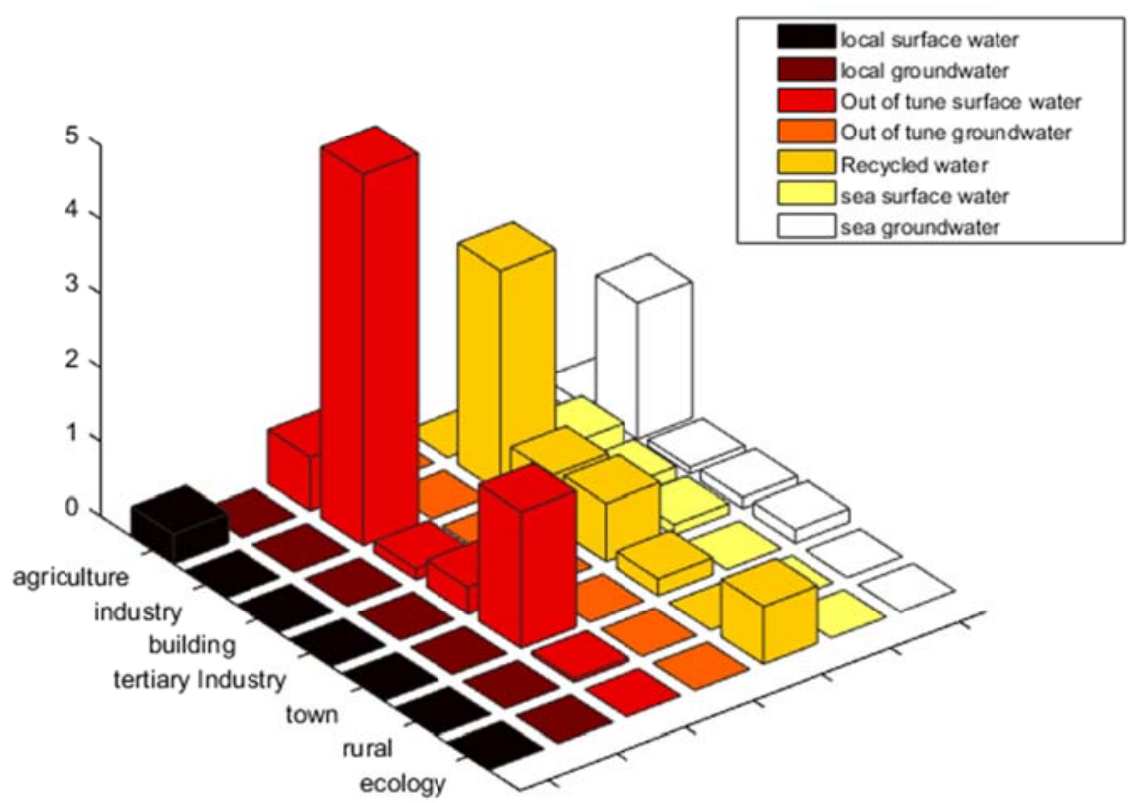

Figure 3. Histogram of water resources distribution of this area in 2020

(3) From the analysis of the source of water in the industrial sector, it can be expected that increasing the use of reclaimed water and seawater can indirectly save a large amount of surface water resources, which is of great significance for the full utilization of water saving and water resources values. Revealing the relationship between supply and demand of water resources, you can visually see the different water demand in the water demand and water demand between the mutual influence, which can provide a reference for water supply scheduling.

(4) Control of environmental pollution, improve the sewage purification rate, in order to increase the amount of water reuse, although this can not directly get high-quality water resources, but through its use in some water sector applications, such as street watering, flushing, resulting in alternative effects, which indirectly save high-quality water resources.

As described in the model, the results obtained in this paper not only meet the water supply constraints, but also ensure the economic and ecological benefits of the integrated optimal, can be 
used as the 2020 water resources allocation planning scientific decision-making basis, at the same time can be refered by water saving work.

\section{Summary}

IFMOP model can reflect the multi-objective, uncertain and fuzzy characteristics of complex system. In this paper, it is applied to the optimization of water resources in eco-city, and can introduce the uncertain information directly in the model construction and solution, which objectively reflect the reality of the problem. Compared with other simple models, IFMOP model has significant advantages.

1) It is found that the IFMOP model is suitable for the optimal allocation of water resources in the eco-city, and it is proved that the IFMOP model has a good applicability in the optimization of water resources in the city.

2) The IFMOP model can be easily decomposed into a simple single-objective linear programming sub-model, using MATLAB tools to solve quickly, with strong operability. The model parameters and optimization of the results are expressed in the form of interval, the dual limitations of observational data and systematic cognition greatly improve the accuracy of the water supply planning and the flexibility of the configuration scheme, which can be directly communicated with decision makers and experts to feed the decision maker's intentions and expert experience into the model. It is good for achieving the mathematical model and the perfect combination of expert knowledge, and being conducive to access to more scientific and rational decision-making.

3) The IFMOP model can reflect the essential characteristics of the optimal allocation of water resources in the eco-city, meet the requirements of the optimal allocation of water resources in the eco-city construction, and obtain the optimal allocation result as the reference value as the scientific basis of the decision-making.

\section{References}

[1] Yanitsky O. The city and ecology [ J]. Nauka Mostkow,1987,1:167-174.

[2] Zhang J, Zhou B G, Zhang L. 2010. Preliminary research on the basic character and development foundation of the ecological city [ J]. Economic Research Guide, 35:72-73.

[3] Bruch E, Atwell J. Agent-based models in empirical social research[J]. Sociological methods \& research, 2015, 44(2): 186-221.

[4] Armitage D R, Plummer R, Berkes F, et al. Adaptive co-management for social-ecological complexity[J]. Frontiers in Ecology and the Environment, 2009, 7(2): 95-102.

[5] Haimes Y Y, Jiang P. Leontief-based model of risk in complex interconnected infrastructures[J]. Journal of Infrastructure systems, 2001, 7(1): 1-12.

[6] Scholz R W, Steiner G. The real type and ideal type of transdisciplinary processes: part I-theoretical foundations[J]. Sustainability Science, 2015, 10(4): 527-544.

[7] Rogers P J. Using programme theory to evaluate complicated and complex aspects of interventions[J]. Evaluation, 2008, 14(1): 29-48.

[8] Sengupta U, Rauws W S, de Roo G. Planning and complexity: Engaging with temporal dynamics, uncertainty and complex adaptive systems[J]. 2016.

[9] Metcalf S. A systems modeling framework for the role of agriculture in a sustainable urban ecosystem[J]. Local Food Systems in Old Industrial Regions: Concepts, Spatial Context, and Local Practices, 2016: 7.

[10]Verburg P H, Schot P P, Dijst M J, et al. Land use change modelling: current practice and research priorities[J]. GeoJournal, 2004, 61(4): 309-32.

[11]Bach P M, Rauch W, Mikkelsen P S, et al. A critical review of integrated urban water modelling-Urban drainage and beyond[J]. Environmental modelling \& software, 2014, 54: 88-107. 
[12]Kelly R A, Jakeman A J, Barreteau O, et al. Selecting among five common modelling approaches for integrated environmental assessment and management[J]. Environmental Modelling \& Software, 2013, 47: 159-181.

[13]Filatova T, Verburg P H, Parker D C, et al. Spatial agent-based models for socio-ecological systems: challenges and prospects[J]. Environmental modelling \& software, 2013, 45: 1-7. 